\title{
CONDITION OF THE BLOOD IN MANIA.
}

\author{
BY \\ W. CHARLES HOOD, M.D., \\ RESIDENT PHYSICIAN TO BETHLEHEM HOSPITAL. \\ Received Feb. 7th.-Read May 8th, 1860.
}

DURing the last four years the attention of many scientific investigators has been directed to the condition of the blood in disease, and the discovery of some very valuable facts has been the result. In gout, for example, Dr. Garrod has shown most conclusively that uric acid is present in very considerable quantity. In certain altered states of the spleen and of the lymphatic glands, Drs. Virchow and Bennett have detected a great increase in the number of white corpuscles; and very recently Dr. Gübler has shown that there is a marked increase of the same white corpuscles during the last stages of cachectic diseases generally. Facts have accumulated indeed, among which there are instances which furnish support to the belief that there is some equivalent change in the blood in all diseases-some change which may give a key to a system of rational treatment; and that the blood in acute mania forms no exception to the general rule may be gathered from the investigations of Drs. Hittorf and Erlenmeyer.

Much remains to be done, however, before we can boast of having any exact knowledge of the state of the blood in insanity, and hence the author, with the able assistance of his friend Dr. Marcet, has been induced to seek for some 
new facts. These facts he has found in a careful analysis of the blood of six maniacal patients during the paroxysm and in a state of convalescence. The author is also duly sensible that much still remains to be done, but at the same time he thinks that the facts already arrived at show clearly (what has not been indicated before) that there is a marked deficiency of fibrine during the period of maniacal excitement and a correction of this deficiency during convalescence; and on this account he begs to submit the following remarks to the notice of the Fellows of the Royal Medical and Chirurgical Society.

\section{Narrative of the Cases and Experiments.}

The six cases selected for experiment were three of acute and three of recurrent mania. An outline of each case, sufficient to show the nature of the attack, with the treatment prescribed, is given, preceded by the chemical analyses of the blood made during the period of maniacal excitement, and afterwards.

\section{Cases of Acute Mania.}

Case 1.-W. G-, æt. 21. Admitted into Bethlehem Hospital in December, 1856. Was previously a draper's assistant. He became maniacal one month before admission. Hereditary tendency was traceable in both his father and paternal grandfather. No known exciting cause. He talked incessantly in a rambling, incoherent manner; was irritable and occasionally violent, at which times he would do injury to others, if not prevented. There was no apparent bodily disease. He was of spare habit, and an excitable temperament. Previous to his admission, he had not been subject to medical treatment. Nourishing diet was prescribed for him, and the following sedative mixture :

$$
\begin{aligned}
& \text { Morphiæ Acetatis, gr. ss ; } \\
& \text { Tinct. Hyoscyam., } 3 \mathrm{j} \text {; } \\
& \text { Mist. Camph., そ̌iss ; ter in die sumend. }
\end{aligned}
$$


At the end of a fortnight the morphia was increased to one grain three times a day, and he continued to take it for many months, but without any apparent benefit. In July his maniacal symptoms abated, and he improved gradually, until September, 1857 (nine months after admission), when he was discharged, perfectly cured.

\section{Analysis of the Blood.}

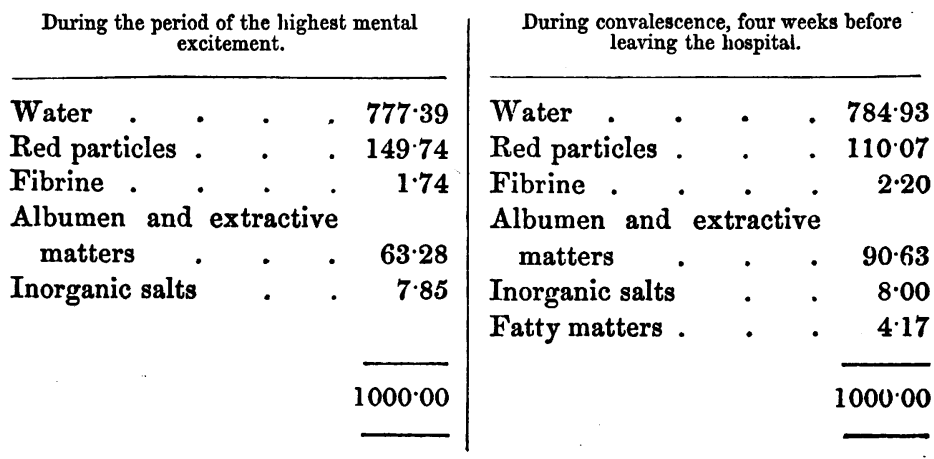

Remarks.-In the analysis made during the maniacal stage, the proportion of every constituent was determined by actual experiment, except the blood-corpuscles, which it was not possible to obtain otherwise than by calculation: The want of consistence in the fibrinous clot was remarkable, and the corpuscles were not at all retained in the network of fibrine, a result which was fully borne out by the chemical analysis. Nothing abnormal could be detected by the microscope.

In the second analysis (taken during the convalescent period), the sample of blood was peculiar, from the circumstance that the serum had a milky-white appearance. The microscopical examination failed to show the presence of fatty globules or of other abnormal anatomical elements. Chemical analysis indicated the existence of a rather large proportion of fatty matters; the fibrine was increased to its normal 
character, but the red particles were below the average. The albumen was rather high, and the inorganic salts somewhat deficient.

CASE 2.-W. T. G-, æt. 33, a drum-major in the Guards, admitted into Bethlehem Hospital in March, 1857; was married, and had lived a steady, temperate life. Strongly built, of a muscular frame, a sanguineous temperament, and shy, retiring habits. Maniacal symptoms first appeared four months before admission, when he underwent medical treatment of an antiphlogistic character in the military hospital. No hereditary tendency could be traced, and the disease appeared to be solely referable to intense study, and an ambitious desire to make himself an accomplished musician. He had many delusions, principally of an exalted and extravagant character. He described himself sometimes as the "Son of God," at other times as an "Earthly Sovereign." He was noisy, mischievous, and incessantly talking.

Morphia and sedatives, with full diet, were prescribed.

In February, 1858, he was so far convalescent as to be allowed to leave the hospital on a month's trial. At the expiration of the month he presented himself again, and was then finally discharged as sane.

Analysis of the Blood.

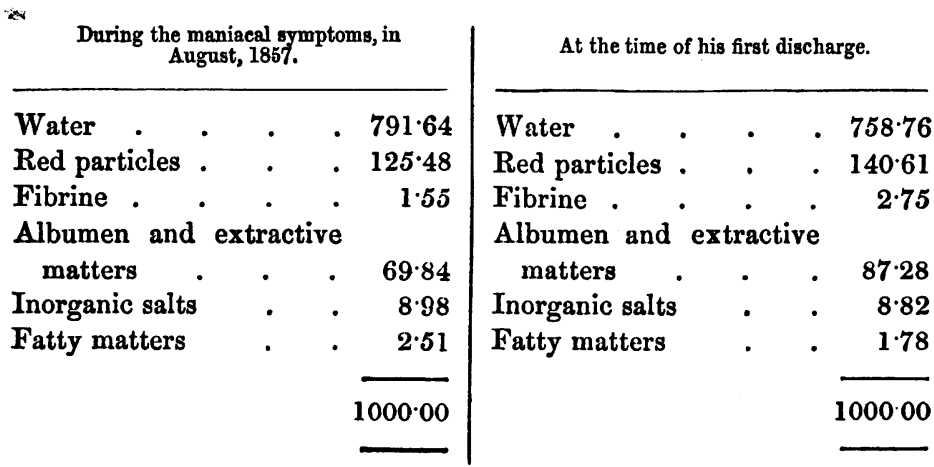


Remarks.-In this case, during the maniacal state there was a remarkable excess of water, and a deficiency of albumen and extractive matters. This increase of water was expected at the commencement of the analysis, from the slow coagulation of the blood during the process of drying in the water bath. The red particles, fatty matters, and inorganic salts were in a more normal proportion; the quantity of fibrine was deficient, being little more than one half its due proportion; the serum was clear, and there was no indication of excess of fat.

In the analysis made during the convalescent stage, the serum was perfectly transparent; it had a slight pink tinge, and was of the natural consistence.

The clot was normal. The proportion of albumen and blood-corpuscles was high, that of water low ; the weight of fibrine normal, but the fat much below the average. It is remarkable that this low proportion of fatty matter was attended with a clear serum. The ashes, or inorganic salts, were in normal proportions; they exhibited a very red colour, probably from their containing a large quantity of peroxide of iron.

Case 3.-E. R-, married, and the mother of four children, admitted into Bethlehem Hospital in June, 1857. She was of a sanguineous temperament, strong passions, and the subject of great sexual excitement, with direct hereditary tendency to mania on the mother's side. She had had three previous attacks since the age of 24, occurring on each occasion during a state of great debility. In the present instance the disease at the time of her admission had lasted one week. For some weeks after admission she was in a sullen and inert condition, seldom speaking to any one, and violent when opposed. She was very dirty in her habits and offensive in her conduct.

The case was treated for several weeks with half-grain doses of tartarized antimony three times daily. This produced no relief, but was followed by rather an aggravation of the symptoms. 
She became excited and mischievous, used very obscene and profane language, and was difficult to manage. Morphia was substituted for the tartarized antimony.

In about eight months the symptoms of insanity suddenly disappeared, and she became cleanly and industrious, cheerful and well behaved. She was discharged quite well at the end of May, 1858.

Analysis of the Blood.

\begin{tabular}{|c|c|c|c|c|}
\hline \multicolumn{2}{|c|}{ During the excited stage, in December. } & \multicolumn{3}{|c|}{ On the day of discharge. } \\
\hline Water & $806 \cdot 71$ & Water & . & $800 \cdot 90$ \\
\hline Red particles & $104 \cdot 68$ & Red particles & . & 109.32 \\
\hline Fibrine & $1 \cdot 67$ & Fibrine & - & 1.75 \\
\hline \multicolumn{2}{|c|}{ Albumen and extractive } & \multicolumn{3}{|c|}{ Albumen and extractive } \\
\hline matters & 76.53 & matters & & $74 \cdot 99$ \\
\hline Inorganic salts & $7 \cdot 41$ & Inorganic salts & . & 8.89 \\
\hline \multirow[t]{2}{*}{ Fatty matters } & $3 \cdot 00$ & Fatty matters & . & $4 \cdot 15$ \\
\hline & $1000 \cdot 00$ & & & $1000 \cdot 00$ \\
\hline
\end{tabular}

Remarks.-In the analysis during the maniacal stage the serum was milky; the clot of natural size and consistence; the proportion of water high, and the other constituents proportionably low; the fatty matters rather above the normal quantity, which might have been expected from the milky appearance of the serum; the fibrine below the average; the albumen and red particles under the normal proportion.

In the second analysis, when convalescence had taken place, the serum was very turbid, and of a nearly white colour. The proportion of water high, and a corresponding deficiency in the weight of the red particles and fibrine. An increase of the fatty matters found actually to exist, as anticipated from the state of the serum; the proportion of inorganic salts was normal, and that of the albumen and extractive matters rather low. 
Cases of Recurrent Mania.

CASE 4.-E. I. G-, æt. 58, a single woman, admitted into Bethlehem Hospital in 1837. When first attacked with mania, the disease was said to be consequent upon extreme grief on account of the death of her father. In this, as in many cases, the disease declared itself by a perversion of her usual habits, demeanour, and conversation. Her ideas became disordered; her language was extremely obscene. She destroyed her clothes, defied all authority, was violent and dangerous. It was necessary to place her in an asylum; and since that time she has been subject to paroxysmal attacks, which are of a most revolting character. Feuchtersleben gives a German physician credit for graphically comparing the movements of a maniac to those of a hyæna confined in a cage, and no untamed creature in the brute creation presents a more deplorable picture than this poor woman during her maniacal paroxysm. She distorts her face with the most hideous grimaces. She utters little, but that little in a growling, inarticulate manner; and her ejaculations and shrieks are of the most revolting character. In this wretched condition she remains during the day, sitting or crouching on the floor, for five consecutive weeks.

The maniacal symptoms then abate, and are followed by a state of composure and perfect sanity, the voice returns to its natural gentle tone, and when she becomes convalescent she is a diligent needle-worker, and her manners are feminine and gentle.

This happy change only lasts a fortnight, at the expiration of which period it is surely followed by a return of the maniacal paroxysm.

The uniform periodicity of these changes is not more painfully interesting to notice than the unvaried similarity of each attack. No excitement appears to hasten the hour of approach. No medical, moral, or hygienic measures hinder its occurrence or rob it of an hour's duration. All 
has been tried, but so certain as the fortnight of peace and mental purity has expired, so surely will the nurse, when the bed-room door is opened in the morning, find the patient out of bed, and lying on the floor in a state of maniacal frenzy.

The patient did not in either attack take medicines, nor was there any alteration made in the diet.

Analysis of the Blood.

During the maniacal stage, May lst, 1857.

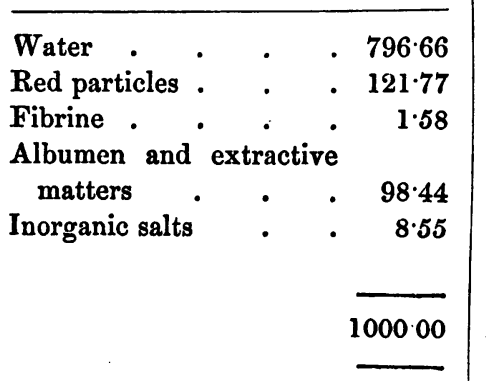

Convalescent stage, Nov. 11th, 1857.

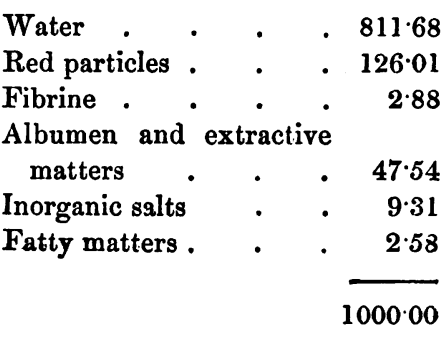

Remarks. - The first analysis shows that the albumen, red particles, and ashes were not far from the normal proportion. The fibrine was decidedly less than in healthy blood.

In the second analysis, at the convalescent period, the blood was found very watery, an excess of inorganic salts, the albumen and extractive matters greatly under the average amount in health. The proportion of fat and red particles were normal. The serum clear but slightly pink, the clot bulky, the proportion of fibrine large.

CAse 5.-F. B-, admitted into Bethlehem Hospital in April, 1838, at the age of 27. The mental disease in this case was clearly traceable to hereditary tendency. The mother, who died insane, left five children, four of whom have 
laboured under the same disorder. F. B - is of an amiable disposition, but living in constant alternations of mental excitement and tranquillity. During the maniacal period she is violent, very obscene and insolent in her conduct, her language and actions bearing a strong impress of sensuality, and her habits dirty and disagreeable. In this state her usual attitude is one of sullen, determined resistance.

There is no fixed regularity in the continuance of the attacks, but whether extending over a shorter or longer period, are followed by seasons of tranquillity, depression, and amiability, her mind regaining its reasoning powers, and her conduct becoming mild and irreproachable. This state of mental alternation has continued for twenty years without any perceptible variation.

Analysis of the Blood.

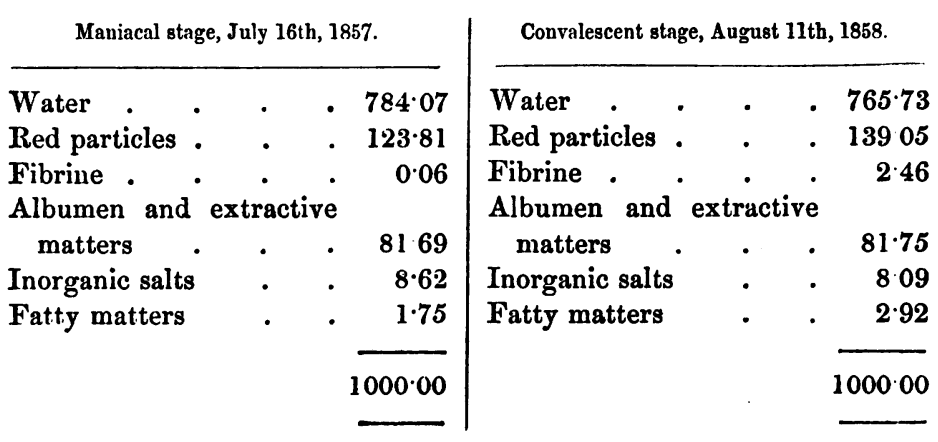

Remarks.-The proportions of the various constituents of the blood were normal, except the fibrine, hardly any traces of which were obtained; that which was secured was of a gelatinous consistence.

In the analysis taken during the convalescent stage, the serum was clear, but rather darker coloured than usual; the clot was very firm and bulky. The colouring matter slightly 
in excess, fibrine normal, and the fatty matters in less proportion than usual.

Case 6.-W. D-, admitted into Bethlehem Hospital in June, 1841, at the age of twenty-nine years, of easy, amiable disposition, and good education.

Expression of countenance varying with the recurrent character of the mental disease; at one time bright and intelligent, at other seasons heavy, repugnant, and almost animal. He was formerly a mercantile clerk. His mental disorder was caused by the grief consequent upon the death of his father. For many years past his condition and delusions have assumed a recurrent periodicity; for a month or six weeks he will be found rational and conversable; during the five succeeding weeks his entire mental condition appears to have undergone a revolution, irritability and passion succeed the amiability, and he has the habits and bearing of a congenital idiot. His conduct is humiliating to witness, oftentimes repulsive, and his personal appearance seems to sympathise with this sad revulsion by assuming even a degraded and animal character. He passes the greater part of the day standing by his accustomed chair at the table, with plate and mug in hand, steadfastly eying the last meal that has been sent to him, and which he obstinately refuses to commence until the succeeding one has been almost finished by his companions. In this routine, he may be found beginning his breakfast as others are leaving the dinner-table, and eating his dinner when his associates are at their evening meal. He smells each piece, and subjects it to strict scrutiny before placing it in his mouth; and thus his day is passed. When convalescent, he willingly takes exercise, seeks pleasure and amusement in reading, playing bagatelle, or draughts, and though never a very lively companion, yet he is sensible and can be agreeable.

The analysis of the blood was taken at such periods as would best represent a fair specimen of each particular state. 
Analysis of the Blood.

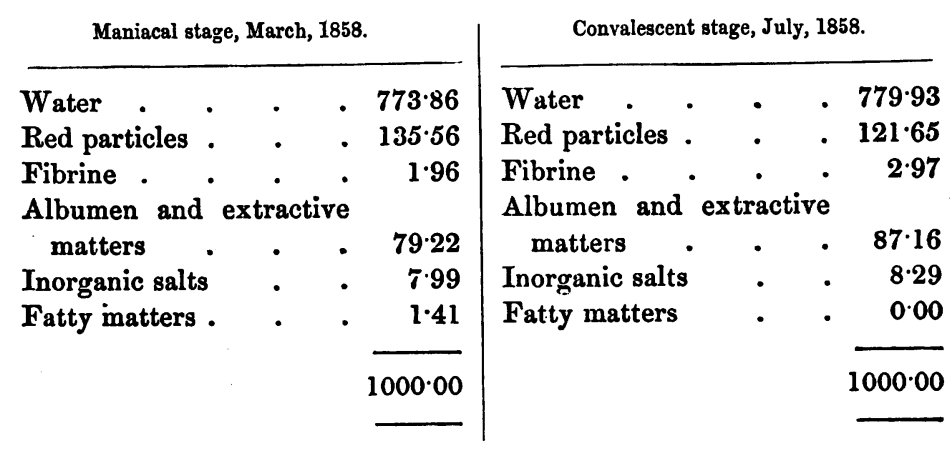

In the analysis, during the maniacal stage, the serum was perfectly clear, and exhibited a pale-yellowish colour, with an alkaline reaction; the clot firm and bulky, had seized upon nearly all the corpuscles; a slight deficiency of albumen and extractive matters, and the proportion of water high. The fibrine was under the normal proportion, and the fats decidedly below the average; the inorganic salts rather low, but not abnormal.

In the convalescent stage, the serum was slightly hazy, and easily separated from the clot, which was very bulky; the proportion of fibrine was normal.

On comparing these cases with those of an analogous character which have been put on record by Drs. Hittorf and Erlenmeyer, the lesson taught by them becomes more pointed and cogent.

The following is the process by which each analysis was obtained :

The blood was drawn by cupping at the nape of the neck, and immediately collected in two small earthenware pots, containing about two ounces each. 
Each analysis was conducted by precisely the same rules and according to the same method, and in each case about the same quantity of blood was extracted.

The analysis was commenced within a few hours of the extraction of the blood, and thus any loss of water, especially in warm weather, was prevented.

In each examination, the blood of one jar was first submitted to analysis for the determination of the albumen, extractive matters, and fibrine; the blood of the other jar being preserved for the determination of the water, globules, fatty matters, and inorganic salts.

In some cases the serum was clear; in others more or less milky; in others slightly tinged with blood-corpuscles.

The jar and serum having been previously weighed, a sample of serum was decanted into a weighed capsule, and the weight of it and its contents immediately ascertained. This serum was then evaporated to dryness in a water bath at $212^{\circ} \mathrm{Fahr}$., the operation being continued until the serum had ceased to lose weight, and care being taken to leave the capsule for a short time in the air-pump vacuum over sulphuric acid previous to weighing it. The blood remaining in the jar (after the serum had been extracted from it, and consisting mostly of the clot) was transferred to a piece of white calico, the corners of which being secured in the shape of a bag, allowed the clot to be thoroughly washed in water, in order to separate the fibrine from the other constituents of the clot. As soon as the fibrine had become colourless it was carefully removed from the cloth by a pair of forceps into a small weighed capsule, and dried in a water bath at $212^{\circ}$ Fahr. until it ceased to lose weight. The weight of the empty jar was finally ascertained.

The second jar having also been weighed, its contents were then transferred to a weighed capsule, and evaporated in a water bath at $212^{\circ} \mathrm{Fahr}$., until the blood had ceased to lose weight, the same precaution being taken as in the case of the serum to leave the dry residue for a short time in the air-pump vacuum over sulphuric acid previous to weighing it. 
The weight of the empty jar was also ascertained. From the dry blood was obtained the weight of the fatty matters and inorganic salts. For this purpose, the whole of the dry blood was pounded, in order to effect a mixture of the dry clot and dry serum, and then a sample was pounded still more finely and dried again (to remove the water it had absorbed during pounding), weighed, and then mixed with sulphuric ether, which dissolved out the fats contained in the finely pounded quantity of the dry blood. The ethereal solution, evaporated to dryness in a weighed capsule, yielded the proportion of fats in the finely pounded dried blood. A sample of the roughly pounded dry blood was placed in a weighed platinum capsule (at the time the blood had been ascertained to be perfectly dry), weighed, and burnt on a small gas flame, the burning being continued until the ashes had ceased to lose weight; thus the proportion of ashes in the dry blood which had been burnt was determined.

From these several data the composition of the blood was calculated.

M. Hittorf has recorded seven cases of acute mania, in which he analysed the blood during the stage of maniacal excitement ; his results are the following: 


\begin{tabular}{|c|c|c|c|c|c|c|c|}
\hline \multirow{3}{*}{ 葛 } & 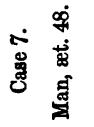 & 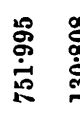 & . & 莕 & जั̀ & $\stackrel{\mathscr{0}}{\dot{\dot{\theta}}}$ & 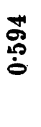 \\
\hline & 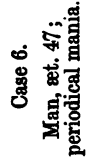 & 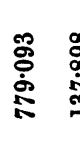 & : & 尽 & "ृ & 嵒 & 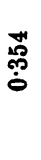 \\
\hline & 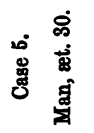 & 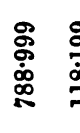 & \& & 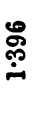 & 曐 & 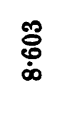 & ఫึ้ \\
\hline \multirow{4}{*}{ 离 } & 总 & 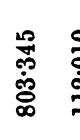 & ב气 & ఫ్తి & 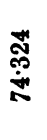 & $\underset{\dot{0}}{\overrightarrow{7}}$ & 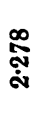 \\
\hline & 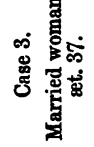 & : & 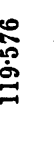 & 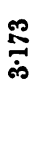 & 芦 & 串 & 范 \\
\hline & 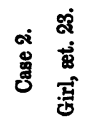 & 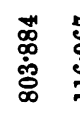 & 兽 & ্ֻণু & 总 & 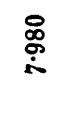 & 弇 \\
\hline & 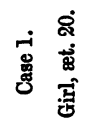 & 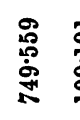 & 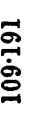 & : & $\begin{array}{l}\dddot{\infty} \\
\stackrel{\infty}{\infty}\end{array}$ & $\begin{array}{l}0 \\
\stackrel{\infty}{\infty} \\
\stackrel{2}{i}\end{array}$ & 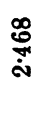 \\
\hline & 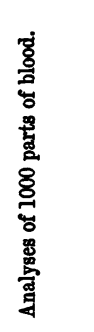 & 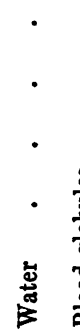 & 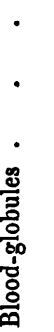 & $\begin{array}{l}\cdot \\
\cdot \\
\cdot \\
\cdot \\
. \\
. \\
.\end{array}$ & 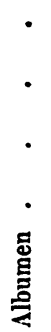 & 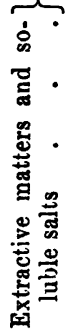 & $\begin{array}{l}\cdot \\
\cdot \\
\cdot\end{array}$ \\
\hline
\end{tabular}


Dr. Hittorf concludes, from these cases, that in acute mania there is a diminution in the amount of the globules, and an increase in the amount of water; but he does not believe that the blood undergoes such a change as to lead $\grave{a}$ priori to the assumption of the fact. We, however, consider that these cases show more than this, and that what they do show is in harmony with our own observation, for in six out of the seven cases, is there not a distinct diminution in the amount of the fibrine of the blood?

M. Erlenmeyer, of the establishment for the insane at Prague, states that he has made 304 analyses of the blood, but principally in cases associated with other internal diseases. He only details three cases, and in two of them mania was accompanied by epilepsy. The blood was drawn during the paroxysm.

\begin{tabular}{|c|c|c|c|}
\hline & $\begin{array}{l}\text { Case 1. } \\
\text { Male, æxt. 66; } \\
\text { violent mania, } \\
\text { recurrent. }\end{array}$ & $\begin{array}{l}\text { Case 2. } \\
\text { Male, æxt. 22; } \\
\text { mania and } \\
\text { epilepsy. }\end{array}$ & $\begin{array}{c}\text { Case } 3 . \\
\text { Male, æat. 34; } \\
\text { mania and } \\
\text { epilepsy. }\end{array}$ \\
\hline 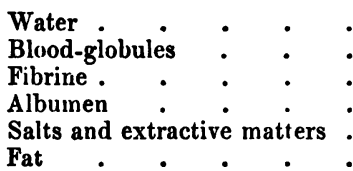 & $\begin{array}{r}798 \cdot 937 \\
114 \cdot 126 \\
1 \cdot 853 \\
73 \cdot 635 \\
10 \cdot 820 \\
0 \cdot 629\end{array}$ & $\begin{array}{r}815 \cdot 747 \\
105 \cdot 596 \\
2 \cdot 301 \\
65 \cdot 830 \\
9 \cdot 811 \\
0 \cdot 715\end{array}$ & $\begin{array}{r}803 \cdot 242 \\
118 \cdot 544 \\
1 \cdot 721 \\
67 \cdot 325 \\
8 \cdot 530 \\
0 \cdot 638\end{array}$ \\
\hline
\end{tabular}

The conclusions drawn by Dr. Erlenmeyer from these cases, and from others which are not quoted, is, that augmentation in the number of red particles, or in the amount of fibrine, is a very unusual occurrence in insanity; and that the opposite state, i.e. diminution of the red particles and increase of serum, is not an unfrequent condition. In two of the three cases given, the amount of fibrine is deficient, but attention is not called to this fact. It is to be observed also, that in the case in which the amount of fibrine was normal, the mania supervened on epilepsy, and the mental paroxysms were coincident with convulsive attacks-so that this case is not one of pure insanity. 
In all these cases, therefore, as will appear in the subjoined table, there is, with only two exceptions, a material deficiency of fibrine in the blood. Of Dr. Hittorf's seven cases, in six the amount of fibrine stands $1 \cdot 3,1 \cdot 4,1 \cdot 8,1 \cdot 9$, $1 \cdot 9,2$; and in the seventh, where this substance is in excess, the excess is very trifling. Of Dr. Erlenmeyer's three cases the fibrine stands $1.7,1 \cdot 8$, in two; and in the third the quantity is normal, being $2 \cdot 3$. While of our own six cases, the fibrine in all falls considerably below the normal standard, and in one very considerably so, the numbers being $1 \cdot 9,1 \cdot 7$, $1 \cdot 6,1 \cdot 5,1 \cdot 5$, and 0.06 . Surely these results express something more than an accidental coincidence.

Having now offered such materials as can be obtained, it may be well to refer to all the cases of acute and recurrent mania in which the blood has been analysed, and for the more ready view place them together in the following table. 


\begin{tabular}{|c|c|c|c|c|c|c|}
\hline \multicolumn{7}{|c|}{ HOOD, BKTHLEH KM. } \\
\hline 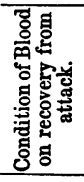 & 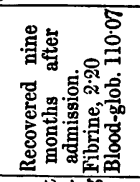 & 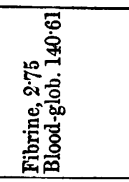 & 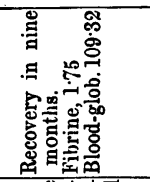 & 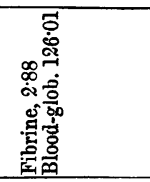 & 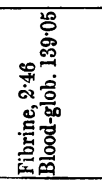 & 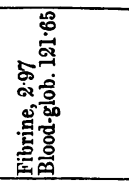 \\
\hline 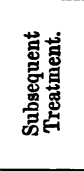 & 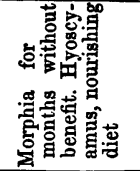 & 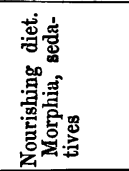 & 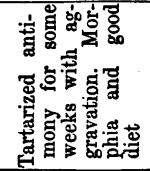 & 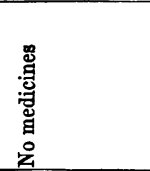 & I & 1 \\
\hline 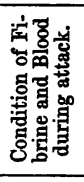 & 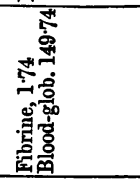 & 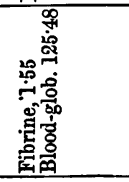 & 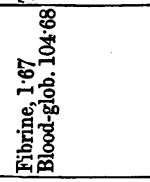 & 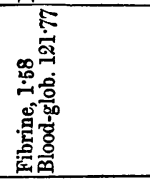 & 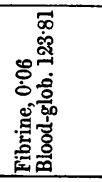 & 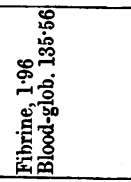 \\
\hline 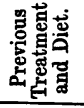 & 1 & 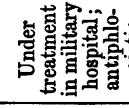 & & 1 & 1 & 1 \\
\hline 莡 & 营 & 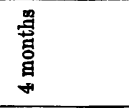 & 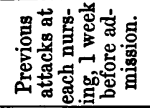 & 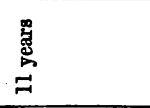 & 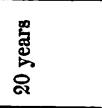 & 总 \\
\hline 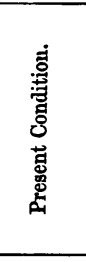 & 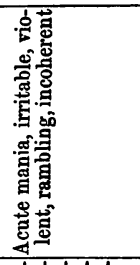 & 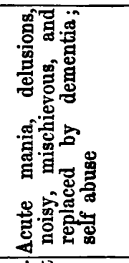 & 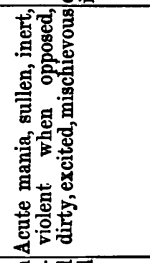 & 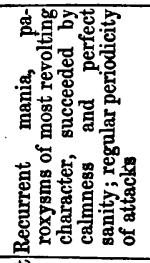 & 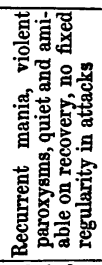 & 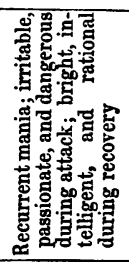 \\
\hline 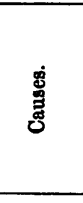 & 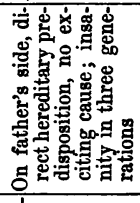 & 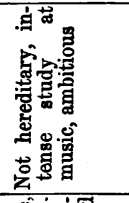 & 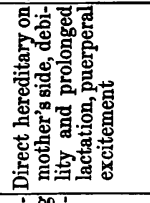 & 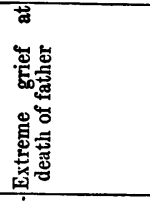 & 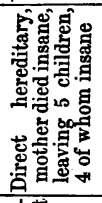 & 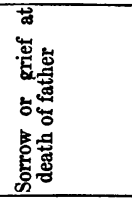 \\
\hline 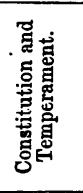 & 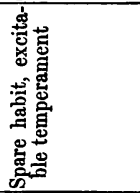 & 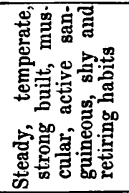 & 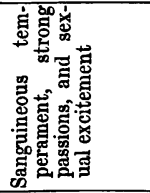 & 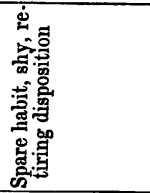 & 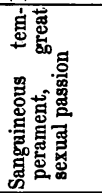 & 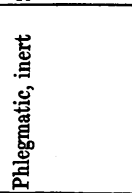 \\
\hline \&5 & สี & 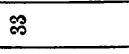 & สิ & $\infty$ & 守 & I \\
\hline 岕 & $\dot{x}$ & $\dot{\Sigma}$ & I. & s & Fi & $\dot{\Sigma}$ \\
\hline 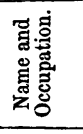 & 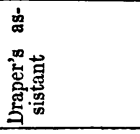 & 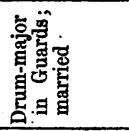 & 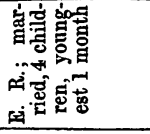 & 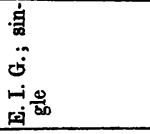 & 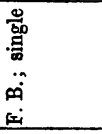 & 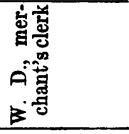 \\
\hline
\end{tabular}


CONDITION OF THE BLOOD IN MANIA.

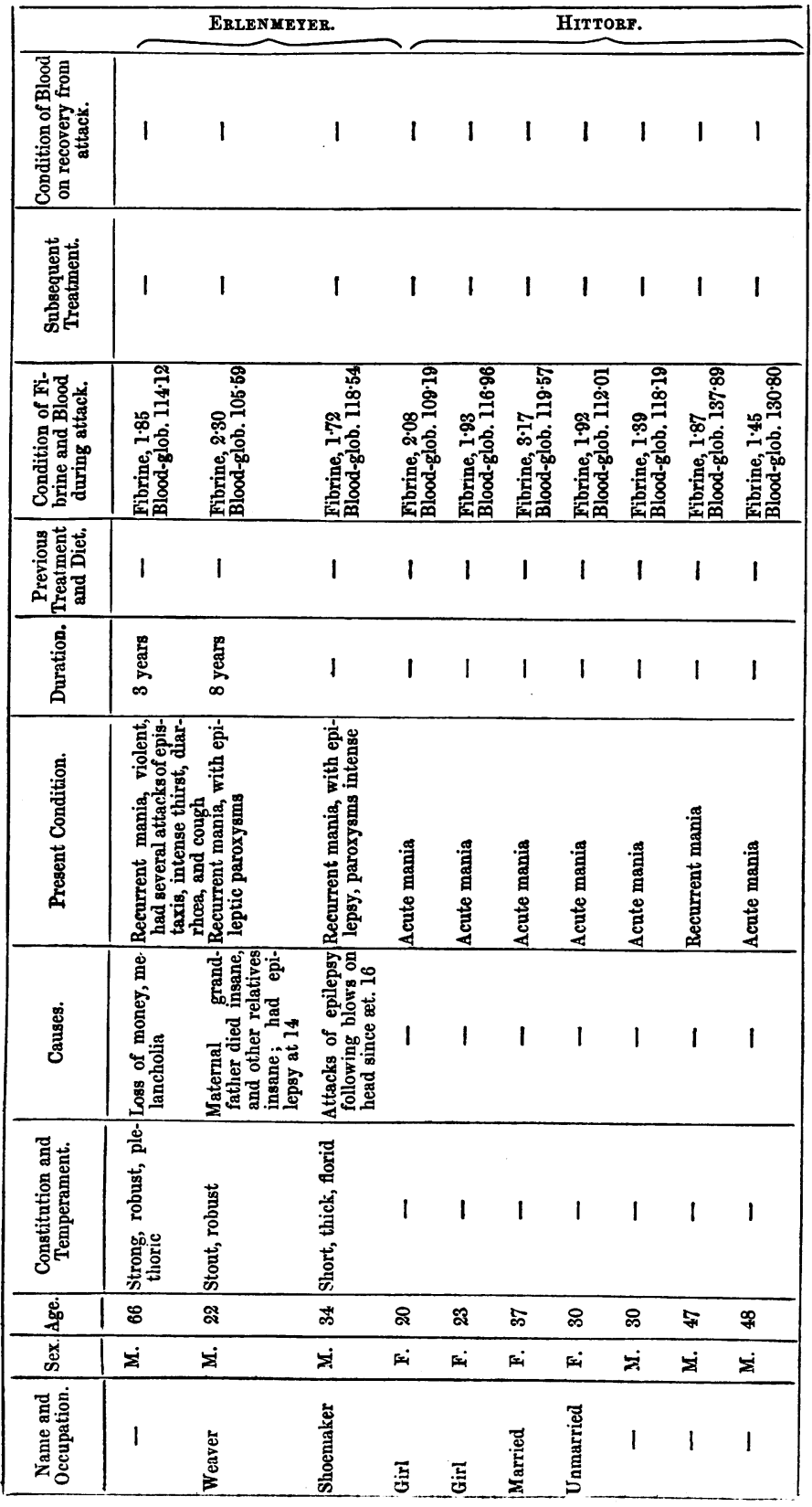

